УДК 634.1:631.541

DOI 10.30679/2219-5335-2020-4-64-25-35

\section{ВОЗМОЖНОСТИ \\ ПОДВОЕВ СЕРИИ СК \\ В ПОВЫШЕНИИ \\ УРОЖАЙНОСТИ ЯБЛОНИ}

Ефимова Ирина Львовна

научный сотрудник

лаборатории питомниководства

Федеральное государственное

бюджетное научное учреждение

«Северо-Кавказский федеральньий

научный иентр садоводства,

виноградарства, виноделия»,

Краснодар, Россия

В статье приведены результаты многолетней комплексной оценки подвоев яблони СК (Северный Кавказ) селекции ФГБНУ СКФНЦСВВ.

Разнообразие биологических свойств подвоев позволяет создавать многолетние насаждения как для определённых технологий возделывания, так и для конкретных почвенноклиматических условий. Использование генетической слаборослости подвоев позволяет регулировать силу роста деревьев, их скороплодность и продуктивность. В условиях изменения климата растёт Значимость устойчивости подвоев погодным стрессам. По результатам многолетней комплексной оценки положительных и отрицательных признаков были рекомендованы для использования в селекции высокоадаптивных слаборослых подвоев яблони: подвой СК 2У как источник признаков скороплодности, зимостойкости, засухоустойчивости; подвои СК 3, СК 4 и СК 7 - как источники слаборослости, скороплодности и зимостойкости. Приведены результаты исследований влияния подвоев СК и степени заглубления при посадке саженцев с высокой окулировкой $(40$ см)
UDC 634.1:631.541

DOI 10.30679/2219-5335-2020-4-64-25-35

\section{POSSIBILITIES \\ OF THE SK SERIES ROOTSTOCKS \\ IN INCREASING \\ THE APPLE TREES YIELD}

\author{
Efimova Irina Lvovna \\ Research Associate \\ of Nursery Plantation Laboratory \\ Federal State Budget \\ Scientific Institution \\ «North Caucasian Federal \\ Scientific Center of Horticulture, \\ Viticulture, Wine-making», \\ Krasnodar, Russia
}

The article presents the results of a multi-year comprehensive assessment of the SC (North Caucasus) apple rootstocks of the FSBSI NCFCHVW breeding. The variety of rootstocks biological properties allows you to create the perennial orchards for certain cultivation technologies, as well as $\mathrm{f}$ or specific soil and climatic conditions. The use of genetic weak vigor of rootstocks allows you to regulate the vigor of tree, their rate of fruitfulness and productivity. In the context of climate change, the importance of rootstock resistance to weather stresses makes more and more significant. Based on the results of a long-standing comprehensive assessment of positive and negative signs, there were recommended for use in the breeding of highly adaptive weakly growing apple rootstocks: the rootstock of SK $2 \mathrm{U}$ as origin of signs of fast fruiting, winter hardiness, drought resistance; rootstocks of SK 3, SK 4 and SK 7 as origin of weak growth, fast fruiting and winter hardiness. The results of research on the influence of rootstocks and the depth degree when planting the seedlings with high oculation $(40 \mathrm{~cm})$ 
на рост и урожайность яблони в саду. На фоне усиления стрессов летнего периода вегетации более глубокая посадка обеспечила лучшие условия для реализации биопотенциала деревьев яблони. У сорта Прикубанское на полукарликовом подвое СК 2У урожай при глубине посадки 25-29 см ожидается на 22,2 \% выше, чем при стандартном заглублении, а у Кубанского багряного (как менее засухоустойчивого сорта) значительно больше - до 2 раз. Преимущество более заглублённой посадки деревьев на подвое СК 4 подтверждается величиной суммарной урожайности за 5 лет плодоношения - превышение к контролю составляет 22-60\%. Внедрение в производство подвоев яблони отечественной селекции, обладающих высоким адаптивным потенциалом в условиях Северного Кавказа, обеспечивает повышение урожайности и стабильности производства, что отвечает критериям стратегии импортозамещения в Российской Федерации.

Ключевые слова: ЯБЛОНЯ, СЕЛЕКЦИЯ, ПОДВОЙ, РОСТ, УРОЖАЙНОСТЬ the growth and yield of apple trees in the garden are presented. Against the background of increasing the stresses of the summer growing season, deeper planting provided the better conditions for the implementation of the apple-trees biopotential. In the Prikubanskoe apple variety on the semi-dwarf rootstock of SK $2 \mathrm{U}$, the yield at a planting depth of $25-29 \mathrm{~cm}$ is expected to be $22.2 \%$ higher than at standard depth, and in the Kuban Bagryanoe (as a less drought-resistant variety) much more up to 2 times. The advantage of more deep planting of trees on the rootstock of SK 4 is confirmed by the value of the total yield for 5 years of fruiting the excess to control is 22-60\%. The introduction of the apple rootstocks domestic breeding with high adaptive capacity under the conditions of the North Caucasus, provides the higher yield capacity and stability of production, meeting the criterions of the import substitution strategy of the Russian Federation.

Key words: APPLE-TREE, BREEDING, ROOTSTOCK, GROWTH, CROP PRODUCTIVITY

Введение. Современные подходы к интенсификации садоводства предполагают создание и использование агробиотехнологий, основанных на биологизации процессов сельскохозяйственного производства, что в полной мере соответствует приоритетному направлению научных исследований в РФ - рациональному природопользованию [1-3].

Наиболее биологизированным и ресурсосберегающим способом существенно повысить эффективность производства плодов яблони является использование высокопродуктивных и адаптивных привойно-подвойных комбинаций, способных противостоять неблагоприятному воздействию био- и абиотических стрессоров среды в условиях меняющегося климата [4-6]. 
Известно, что биологические особенности подвоев значительно влияют на силу роста, скороплодность, продуктивность и стабильность плодоношения привитого дерева, его устойчивость к изменениям окружающей среды [7-10]. Именно адаптивность подвоя в определённой мере определяет реакцию привитого растения на внешние условия и в связи с этим размах изменчивости урожайности [11-14].

Этим объясняется наличие многочисленных исследований по селекции и сортоизучению подвоев яблони [6-9], оценке их влияния на рост и урожайность привитых сортов [15-17]. Особое внимание уделяется оценке адаптивного потенциала подвоев и привойно-подвойных комбинаций в новых погодных условиях, возникших в связи с наблюдаемой в последнее десятилетие изменчивостью климата [18-21].

Приоритетными являются научные исследования, направленные на выявление реакций плодовых на разнообразные абиотические стрессоры, результаты которых позволяют в процессе экологического сортоиспытания выявить наиболее адаптивные генотипы подвоев для их районирования.

В современных промышленных насаждениях яблони обязательным конструкционным элементом интенсивной технологии ведения сада на карликовых подвоях является использование стационарной опоры (шпалеры), что существенно удорожает себестоимость продукции.

Новым низкозатратным способом повышения эффективности насаждений яблони на карликовых и полукарликовых подвоях является использование саженцев нового типа - с высотой окулировки 40 см в сочетании с заглублённой посадкой.

Изучение влияния подвоев СК и степени заглубления саженцев с высокой окулировкой на изменение ростовых и продукционных процессов у деревьев яблони в саду представляет большой теоретический и практический интерес, так как ранее в агротехнических правилах 
указывали на опасность заглублённой посадки саженцев, приводящей к угнетению роста пяточных корней [22].

Более широкое использование в производстве подвоев яблони серии СК отечественной селекции, обладающих высоким адаптивным потенциалом в условиях Северного Кавказа, позволит повысить эффективность регионального садоводства, что в полной мере отвечает критериям стратегии импортозамещения в Российской Федерации.

Объекты и методы исследований. Исследования проводились в ОПХ «Центральное» (г. Краснодар) на маточнике отводочных подвоев, возделываемом по технологии размножения горизонтальными отводками с использованием в качестве мульчирующего материала рисовой шелухи, а также в опытном саду 2013 года посадки (схема размещения 4x0,9 и 4х1,2 м), условно орошаемом, с залужением почвы сеяными травами.

Объектом исследований были подвои яблони различного происхождения и деревья яблони сорта Прикубанское на подвоях СК 2У, СК 4 и СК 7, высаженные в сад саженцами с высотой окулировкой 40 см, с установкой посадочного кола и различной степенью заглубления.

Биометрические показатели и урожайность растений определяли по общепринятым методикам селекции и сортоиспытания [23, 24].

Обработку полученных экспериментальных данных осуществляли методами математической статистики с применением дисперсионного анализа в программе Microsoft Office Excel 2003.

Обсуждение результатов. Известно, что климатические условия региона выращивания в решающей степени определяют состояние и урожайность любых сельскохозяйственных растений. Для плодовых деревьев это особенно важно, так как неблагоприятные погодные явления (стрессы) могут спровоцировать у них повреждения различных органов и тканей, что 
Плодоводство и виноградарство Юга России № 64(4), 2020 г.

в свою очередь проявляется в снижении или даже полной гибели урожая. Наиболее вредоносным стрессором летнего периода вегетации для плодовых в условиях меняющегося климата является высокая температура воздуха, значительно превышающая многолетние показатели, в комплексе с недобором осадков и засухой.

Анализ изменений за последние 30 лет одного из наиболее информативных метеопоказателей - среднесуточной температуры воздуха - выявил тренд ее превышения над среднемноголетними значениями. Так, превышение средней температуры воздуха в наиболее жарком 2018 году уже в мае составило $4,4^{\circ} \mathrm{C}$. Далее среднемноголетние значения были превзойдены ежемесячно на 0,9-5,4 ${ }^{\circ} \mathrm{C}$, а максимальное превышение было в июне $\left(5,4{ }^{\circ} \mathrm{C}\right)$, в конце августа $\left(4,2^{\circ} \mathrm{C}\right)$ и начале сентября $\left(4,2^{\circ} \mathrm{C}\right)$.

В 2020 году май был жарче на 0,8, а июнь на 3,3 ${ }^{\circ} \mathrm{C}$, а максимальная температура в июне $\left(35^{\circ} \mathrm{C}\right)$ подходила вплотную к экстремальным значениям в $36{ }^{\circ} \mathrm{C}$.

В этих условиях урожайность плодовых растений в существенной степени зависит от генотипически обусловленной засухоустойчивости компонентов (сортов и подвоев) различных привойно-подвойных комбинаций (ППК). При этом устойчивость к температурным стрессам привитого дерева в значительной степени обусловлена степенью засухоустойчивости непосредственно самого подвоя.

Определение засухоустойчивости различных подвоев яблони в маточнике проводилось лабораторно-полевым методом в условиях повышенного температурного фона (рис. 1).

В результате исследований установлено, что в карликовой группе подвои серии СК превзошли по оводнённости листьев контроль засухоустойчивый подвой М 9 (58,3 \%), при этом наибольшая оводнённость листьев отмечена у подвоя СК 4 (64,6 \%). 


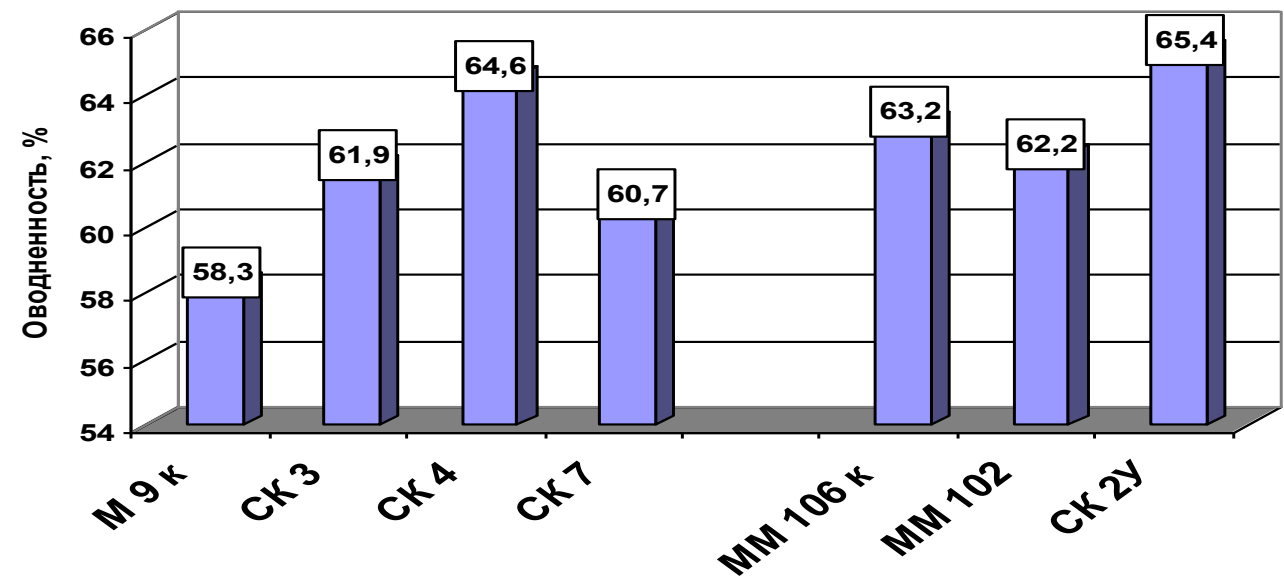

Рис.1. Оводнённость листьев подвоев яблони (маточник ОПХ «Центральное», г. Краснодар, 07.07.2020)

В группе полукарликовых подвой СК 2У (65,4 \%) показал большую оводнённость листьев, чем у подвоев ММ 106 и ММ 102 (63,2 и 62,2 \%).

Оценка водоудерживающей способности листьев показала, что лучше других удерживали воду листья подвоев СК 4 и СК 2У (рис. 2).

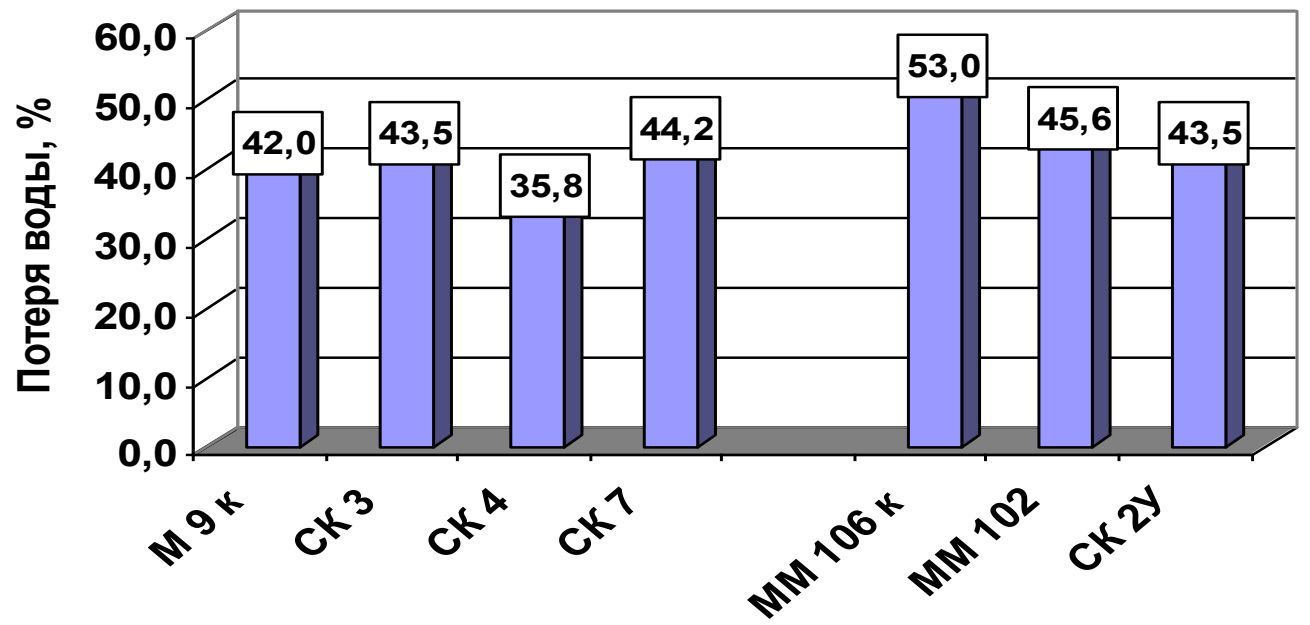

Рис. 2. Водоудерживающая способность листьев подвоев яблони (маточник ОПХ «Центральное», г. Краснодар, 07.07.2020)

Таким образом, в условиях рано наступившей высокой температуры, явившейся сильным стрессом для растений, лучшую адаптивность по сравнению с интродуцентами показали подвои яблони серии 
СК местной селекции. Генотипически обусловленная приспособленность подвоев СК в условиях меняющегося климата к более жарким и засушливым условиям выращивания обеспечила стабильность ростовых и продукционных процессов привитых на них деревьев яблони при наступлении погодных стрессов.

По результатам проведенных ранее исследований устойчивости подвоев яблони к повреждающим факторам зимы, а также изучения реализации их продукционного потенциала, были рекомендованы для использования в селекции высокоадаптивных слаборослых подвоев яблони: подвой СК 2У как источник признаков скороплодности, зимостойкости, засухоустойчивости; подвои СК 3, СК 4 и СК 7 - как источники слаборослости, скороплодности и зимостойкости.

Использование в промышленном садоводстве подвоев яблони серии СК, обладающих высоким адаптивным потенциалом, позволит существенно повысить эффективность производства плодов яблони в условиях ухудшения комфортности метеопараметров во время весенне-летнего периода вегетации плодовых на Северном Кавказе.

Для экономичного решения проблемы слабой якорности в саду деревьев на слаборослых подвоях, было предложено вместо установки постоянной опоры закладывать такие насаждения саженцами с высотой окулировки 40 см с последующей их заглублённой посадкой.

В результате исследований были выявлены закономерности влияния нового типа посадочного материала (саженцы с высокой окулировкой) на изменение ростовых, физиологических и продукционных процессов у яблони в условиях увеличения амплитуды изменчивости метеофакторов.

Установлено, что на фоне усиления стрессов летнего периода вегетации, связанного с более ранним в 2020 году (май-июнь) наступлением высоких температур воздуха, более глубокая посадка таких саженцев обеспечила лучшие условия для реализации их биопотенциала. 
У деревьев яблони сорта Прикубанское на полукарликовом подвое СК 2У урожай при глубине расположения пяточных корней 25-29 см ожидается на 22,2 \% выше, чем при стандартном заглублении, а у Кубанского багряного (как менее засухоустойчивого сорта) значительно больше - до 2 раз.

У деревьев яблони с высокой окулировкой на карликовых подвоях (сорт Кубанское багряное на подвое СК 4) урожайность в 2020 году прямо коррелирует с увеличением глубины посадки $(\mathrm{r}=0,89)$, при этом наибольшим (на 40 \% выше контроля) ожидается урожай при глубине посадки 30-35 см. Преимущество более заглублённой посадки деревьев на карликовом подвое СК 4 подтверждается суммарной урожайностью за 5 лет плодоношения - превышение к контролю составляет 22-60 \%.

Достигнутый положительный эффект заглублённой посадки объясняется более комфортным для функционирования корневых систем режимом температуры и влажности почвы, что становится особо значимым в условиях повышенной температуры не только воздуха, но и верхнего слоя почвы.

Bblвodbl. В условиях рано наступившего высокотемпературного стресса, лучшую адаптивность по сравнению с интродуцентами показали подвои яблони серии СК местной селекции. Генотипически обусловленная приспособленность подвоев СК к более жарким и засушливым условиям выращивания обеспечила стабильность ростовых и продукционных процессов привитых деревьев яблони при наступлении погодных стрессов.

По результатам комплексных исследований, были рекомендованы для использования в селекции высокоадаптивных слаборослых подвоев яблони: подвой СК $2 У$ как источник признаков скороплодности, зимостойкости, засухоустойчивости; подвои СК 3, СК 4 и СК 7 - как источники слаборослости, скороплодности, зимостойкости. 
Плодоводство и виноградарство Юга России № 64(4), 2020 г.

Более глубокая посадка саженцев с высокой окулировкой обеспечила лучшие условия для реализации биопотенциала деревьев яблони на карликовом и полукарликовом подвое.

Высокий адаптивный потенциал отечественных подвоев яблони СК обеспечивает повышение эффективности производства плодов яблони при снижении комфортности погодных условиях во время весенне-летнего периода вегетации плодовых на Северном Кавказе.

\section{Литература}

1. Еремин Г.В., Ефимова И.Л. Подвои семечковых и косточковых культур для современных интенсивных промышленных технологий // Разработки, формирующие современный облик садоводства. Монография. Краснодар: ГНУ СКЗНИИСиВ. 2011. C. 118-139.

2. Причко Т.Г., Ефимова И.Л. Развитие научного направления «Промышленное интенсивное садоводство на юге России и его основные достижения» // Садоводство и виноградарство. № 4. 2016. С. 47-52.

3. Трусевич Г.В. Интенсивное садоводство. М.: Россельхозиздат, 1978. 274 с.

4.Ефимова И.Л., Ермоленко В.Г. Подвои яблони // Современные методологические аспекты организации селекционного процесса в садоводстве и виноградарстве. Краснодар: СКЗНИИСиВ, 2012. С. 301-312.

5. Соломатин Н.М. Генофонд вегетативно размножаемых форм яблони для улучшения сортимента подвоев, сырьевых и декоративных сортов в условиях ЦЧР: автореф. дис. ... д-ра с.-х. наук: 06.01.05 / Соломатин Николай Михайлович. Москва, $2018.42 \mathrm{c}$.

6. Каталог паспортов доноров и источников селекционно-значимых признаков садовых культур и винограда: Учебно-методическое пособие / Е.А. Егоров, Е.В. Ульяновская, Р.Ш. Заремук [и др.]. Краснодар: ФГБНУ СКФНЦСВВ, 2019. 215 с.

7. Role of apple clonal rootstocks on yield, fruit size, nutritional value and antioxidant activity of 'Red Chief ${ }^{\circledR}$ Camspur' cultivar / Tomo Milošević, Nebojša Milošević, Jelena Mladenović// Scientia Horticulturae, Volume 236, 16 June 2018, Pages 214-221. // https://doi.org/10.1016/j.scienta.2018.03.050

8.Yi Wang, Progress of Apple Rootstock Breeding and Its Use / Wei Li, Xuefeng Xu, Changpeng Qiu, Ting Wu, Qinping Wei, Fengwang Ma, Zhenhai Han // Horticultural Plant Journal, Volume 5, Issue 5, 2019, Pages 183-191//https://doi.org/10.1016/j.hpj.2019.06.001

9. Univer T., Kviklys D., Lepsis J., Univer N. Early performance of 'Auksis' apple trees on dwarfing rootstocks in Baltic region // Agronomy Research. - 2010. - № 8 - P. 753-748.

10. Wrona D., Sadowski A. Comparison of 18 apple rootstocks for apple tree cv. 'Elisa' in V planting system // Sodininkystè ir Daržininkystè. - 2006. - № 25. - P. 144-150.

11. Оценка взаимодействия генотипов привоя и подвоя яблони с использованием биометрических методов / Драгавцева И.А., Драгавцев В.А., Ефимова И.Л. [и др.]. // Сельскохозяйственная биология. 2015. Том 50. № 5. С. 590-599.

12. К экспериментальному подтверждению новой гипотезы об экологогенетической природе феномена «взаимодействия генотип-среда» / В.А. Драгавцев [и др.] // Сельскохозяйственная биология. 2018. №53(01). С. 151-156. 
13. Захарчук Н. В. Диагностические критерии экспересс-оценки устойчивости яблони к перегреву [Электронный ресурс] // Плодоводство и виноградарство Юга России. 2012. № 17(5). С. 64-68. URL: http://journalkubansad.ru/pdf/12/05/08.pdf. (дата обращения: 16.07.2020).

14. Ефимова И.Л. Влияние генотипа подвоя на урожайность яблони в стрессовых условиях среды [Электронный ресурс] // Плодоводство и виноградарство Юга России. 2012. № 17(5). С. 22-27. URL: http://journalkubansad.ru/pdf/12/05/03.pdf. (дата обращения: 16.07.2020).

15. Lepsis J., 2006. Evaluation of apple rootstock Pure 1. Latvian Journal of Agronomy, 9: 75-79.

16. A. Czynczyk, P. Bielicki, T.L. Robinson. Seven-Year Evaluation of Geneva and Polish Rootstocks with "Golden Delicious Reinders" Apple in Poland // Journal of the American Pomological Society. - 2010. - Vol. 64. - № 1. - P. 50-51.

17. Khanizadeh, S. SJM15» applerootstock / S. Khanizadeh, Y. Groleau, A. Levasseur, O. Carisse, V. Toussaint, R. Granger, G. Rousselle // International Journal of Fruit Science. - 2007. - Vol. 7, № 3. - P. 27-31.

18. Maas F.M., Wertheim S.J., 2004. A multi-site rootstock trial with the apple cultivars 'Cox's Orange Pippin' and 'Jonagold'. Acta Horticulturae, 658: 177-184.

19. Эффекты взаимодействия «генотип-среда» для плодовых культур в изменяющихся погодных условиях юга России (во времени и в пространстве) / И.А. Драгавцева [и др.]. // Труды Кубанского государственного аграрного университета. 2017. № 67. C. 36-43.

20. Generative developments and pomological traits of apple (MALUS X DOMESTICA Borkh.) scion cultivars canopy on dwarf clonal rootstocks in dry temperate ecosystem of north-west Himalayas / Pramod Kumar, Rajeshwar S.Chandel // Scientia Horticulturae, Volume 215, 27 January 2017, Pages 28-37 // https://doi.org/10.1016/j.scienta.2016.12.012

21. Фисенко А.Н., Егоров Е.А., Попова В.П. Низкозатратная технология высокопродуктивных садов яблони на слаборослых подвоях. Краснодар: СКЗНИИСиВ, 1999. $52 \mathrm{c}$.

22. Программа и методика сортоизучения плодовых, ягодных и орехоплодных культур / Под общ. ред. Е.Н. Седова и Т.П. Огольцовой. Орёл, 1999. 606 с.

23. Программа Северо-Кавказского центра по селекции плодовых, ягодных, цветочно-декоративных культур и винограда на период до 2030 года / Под ред. Е.А. Егорова, Г.В. Еремина, И.А. Ильиной [и др.]. Краснодар: ГНУ СКЗНИИСиВ, 2013. 202 с.

\section{References}

1. Eremin G.V., Efimova I.L. Podvoi semechkovyh i kostochkovyh kul'tur dlya sovremennyh intensivnyh promyshlennyh tekhnologij // Razrabotki, formiruyushchie sovremennyj oblik sadovodstva. Monografiya. Krasnodar: GNU SKZNIISiV. 2011. S. 118-139.

2. Prichko T.G., Efimova I.L. Razvitie nauchnogo napravleniya «Promyshlennoe intensivnoe sadovodstvo na yuge Rossii i ego osnovnye dostizheniya»// Sadovodstvo i vinogradarstvo. № 4. 2016. S. 47-52.

3. Trusevich G.V. Intensivnoe sadovodstvo. M.:Rossel'hozizdat, 1978. $274 \mathrm{s.}$

4. Efimova I.L., Ermolenko V.G. Podvoi yabloni // Sovremennye metodologicheskie aspekty organizacii selekcionnogo processa $\mathrm{v}$ sadovodstve i vinogradarstve. Krasnodar: SKZNIISiV, 2012. S. 301-312.

5. Solomatin N.M. Genofond vegetativno razmnozhaemyh form yabloni dlya uluchsheniya sortimenta podvoev, syr'evyh i dekorativnyh sortov v usloviyah CChR: avtoref. dis. ... d-ra s.-h. nauk: 06.01.05 / Solomatin Nikolaj Mihajlovich. Moskva, 2018. 42 s. 
6. Katalog pasportov donorov i istochnikov selekcionno-znachimyh priznakov sadovyh kul'tur i vinograda: Uchebno-metodicheskoe posobie / E.A. Egorov, E.V. Ul'yanovskaya, R.Sh. Zaremuk [i dr.]. Krasnodar: FGBNU SKFNCSVV, 2019. 215 s.

7. Role of apple clonal rootstocks on yield, fruit size, nutritional value and antioxidant activity of 'Red Chief ${ }^{\circledR}$ Camspur' cultivar / Tomo Milošević, Nebojša Milošević, Jelena Mlade-nović// Scientia Horticulturae, Volume 236, 16 June 2018, Pages 214-221. // https://doi.org/10.1016/j.scienta.2018.03.050

8.Yi Wang, Progress of Apple Rootstock Breeding and Its Use / Wei Li, Xuefeng Xu, Changpeng Qiu, Ting Wu, Qinping Wei, Fengwang Ma, Zhenhai Han // Horticultural Plant Journal, Volume 5, Issue 5, 2019, Pages 183-191//https://doi.org/10.1016/j.hpj.2019.06.001

9. Univer T., Kviklys D., Lepsis J., Univer N. Early performance of 'Auksis' apple trees on dwarfing rootstocks in Baltic region // Agronomy Research. - 2010. - № 8 - P. 753-748.

10. Wrona D., Sadowski A. Comparison of 18 apple rootstocks for apple tree cv. 'Elisa' in V planting system // Sodininkyste ir Daržininkystè. - 2006. - № 25. - P. 144-150.

11. Ocenka vzaimodejstviya genotipov privoya i podvoya yabloni $\mathrm{s}$ ispol'zovani-em biometricheskih metodov / Dragavceva I.A., Dragavcev V.A., Efimova I.L. [i dr.]. // Sel'skohozyajstvennaya biologiya. 2015. Tom 50. № 5. S. 590-599.

12. K eksperimental'nomu podtverzhdeniyu novoj gipotezy ob ekologo-geneticheskoj prirode fenomena «vzaimodejstviya genotip-sreda»/ V.A. Dragavcev [i dr.] // Sel'skohozyajstvennaya biologiya. 2018. №53(01). S. 151-156.

13. Zaharchuk N. V. Diagnosticheskie kriterii eksperess-ocenki ustojchivosti yabloni k peregrevu [Elektronnyj resurs] // Plodovodstvo i vinogradarstvo Yuga Rossii. 2012. № 17(5). S. 64-68. URL: http://journalkubansad.ru/pdf/12/05/08.pdf. (data obrashcheniya: 16.07.2020).

14. Efimova I.L. Vliyanie genotipa podvoya na urozhajnost' yabloni v stressovyh usloviyah sredy [Elektronnyj resurs] // Plodovodstvo i vinogradarstvo Yuga Rossii. 2012. № 17(5). S. 22-27. URL: http://journalkubansad.ru/pdf/12/05/03.pdf. (data obrashcheniya: 16.07.2020).

15. Lepsis J., 2006. Evaluation of apple rootstock Pure 1. Latvian Journal of Agronomy, 9: 75-79.

16. A. Czynczyk, P. Bielicki, T.L. Robinson. Seven-Year Evaluation of Geneva and Polish Rootstocks with |"Golden Delicious Reindersl" Apple in Poland // Journal of the Ameri-can Pomological Society. - 2010. - Vol. 64. - № 1. - R. 50-51.

17. Khanizadeh, S. SJM15» applerootstock / S. Khanizadeh, Y. Groleau, A. Levasseur, O. Carisse, V. Toussaint, R. Granger, G. Rousselle // International Journal of Fruit Science. - 2007. - Vol. 7, № 3. - R. 27-31.

18. Maas F.M., Wertheim S.J., 2004. A multi-site rootstock trial with the apple cultivars 'Cox's Orange Pippin' and 'Jonagold'. Acta Horticulturae, 658: 177-184.

19. Effekty vzaimodejstviya «genotip-sreda» dlya plodovyh kul'tur v izmenyayushchihsya pogodnyh usloviyah yuga Rossii (vo vremeni i v prostranstve) / I.A. Dragavceva [i dr.]. // Trudy Kubanskogo gosudarstvennogo agrarnogo universiteta. 2017. № 67. S. 36-43.

20. Generative developments and pomological traits of apple (MALUS X DOMESTICA Borkh.) scion cultivars canopy on dwarf clonal rootstocks in dry temperate ecosystem of north-west Himalayas / Pramod Kumar, Rajeshwar S.Chandel // Scientia Horticulturae, Volume 215, 27 January 2017, Pages 28-37 // https://doi.org/10.1016/j.scienta.2016.12.012

21. Fisenko A.N., Egorov E.A., Popova V.P. Nizkozatratnaya tekhnologiya vysokoproduktivnyh sadov yabloni na slaboroslyh podvoyah. Krasnodar: SKZNIISiV, 1999. $52 \mathrm{s.}$

22. Programma i metodika sortoizucheniya plodovyh, yagodnyh i orekhoplodnyh kul'tur / Pod obshch. red. E.N. Sedova i T.P. Ogol'covoj. Oryol, 1999. 606 s.

23. Programma Severo-Kavkazskogo centra po selekcii plodovyh, yagodnyh, cvetochno-dekorativnyh kul'tur i vinograda na period do 2030 goda / Pod red. E.A. Egorova, G.V. Eremina, I.A. Il'inoj [i dr.]. Krasnodar: GNU SKZNIISiV, 2013. 202 s. 